\title{
La dirección profesionalizada del hospital y la participación de los profesionales: una necesidad acuciante
}

\section{José Luis De Sancho Martín}

Arbor CLXX, 670 (Octubre 2001), 317-324 pp.

La simbiosis de los dos conceptos que se enumeran en esta ponencia, se analizan conjuntamente, con un enfoque que trata de demostrar que no hay contradicción entre lo que son dos exigencias cada día más evidentes, como son la de tender hacia equipos directivos expertos, bien formados, profesionales de la dirección, pero que desarrollen su labor en base a politicas de personal que se orienten a la participación e implicación de los profesionales. Todo ello exigirá una adecuación de las normativas que allane el camino a fórmulas más eficientes de gestión y participación.

\section{Introducción}

Colaboro gustosamente en esta Monografía de la Revista Arborciencia con un tema frecuentemente debatido en los últimos años en Congresos y Jornadas de gestión hospitalaria, Mesas redondas de Consejeros de Salud, y con cuyas conclusiones, siempre en la misma línea, podría ya concluir el tema que me asigna el coordinador de esta Monografía: es absolutamente necesario y urgente profesionalizar la $d i$ - 
rección de los hospitales públicos de nuestro País, de la misma forma que es urgente y obligada la participación activa de los profesionales (médicos y enfermeros particularmente) en la gestión del hospital, acercando posturas y disminuyendo las resistencias al cambio organizativo que precisan los hospitales en el final de siglo que vivimos.

Analizaré en cualquier caso en este artículo de donde venimos, el tránsito llevado a cabo en estos últimos años y las perspectivas a afrontar en el ya sí inminente siglo XXI, que permitan afrontar con realismo y optimismo la gestión hospitalaria en el nuevo siglo.

\section{Análisis de situación}

Existe consenso prácticamente general sobre la consideración del hospital como una empresa, con características diferenciales sustanciales de las empresas del sector industrial, de forma que dicha consideración va siempre ligada a la denominación «Empresa de Servicios», y en ocasiones, de «Empresa de servicios de salud», siendo su producto final, la «mejora o recuperación de la salud».

Pero sea cual sea su denominación, tiene unas características que la diferencian y que hacen compleja su dirección, hasta el punto de hacer decir a autoridades del mundo empresarial como P. Drucker que «el hospital es la empresa más compleja de dirigir», o como decía jocosamente F. Moreu en un artículo en Todo Hospital, el hospital es junto a la orquesta municipal de San Sebastián y la Universidad, una de las empresas más difíciles de dirigir... porque están llenas de artistas... y los artistas son difíciles de introducir en la cultura empresarial.

Bromas aparte, resulta cierto que el entorno administrativo en el que se ha movido la gestión del hospital hasta los 80, y que aún perdura en parte, no tiene nada que ver con el entorno empresarial que se pretende en el inmediato futuro.

La cultura de gestión administrativa basada en el rechazo del riesgo, un bajo nivel de incentivación tangible y un gran peso de la burocracia, ha generado un modelo de gestión de continuidad, con excesiva centralización, y bajos niveles de autonomía, muy reglamentista, y con grandes dificultades para la introducción de nuevos instrumentos de gestión en el pasado reciente.

Una dinámica empresarial genera una cultura de gestión distinta, basada en la búsqueda del beneficio, la aceptación del riesgo, la selección de oportunidades, un alto nivel de incentivación tangible y una gran capacidad para captar el cambio y la innovación. 
La dirección profesionalizada del hospital.....

El modelo de gestión empresarial se basa en el pensamiento estratégico, una gran autonomía y una orientación comercial, todo lo cual parece conveniente incorporar a la gestión del hospital, incluso siendo este público y sin ánimo de lucro.

En resumen, del entorno hospitalario tradicional en el que nos hemos movido, es preciso pasar a un entorno empresarial, con premisas claramente dierenciadas, en las que aparecen el riesgo en la toma de decisiones, la flexibilidad organizativa y la competencia, hasta ahora inexistentes prácticamente.

Estas conclusiones, que parecen recientes en el tiempo, las argumentaba ya aquel Director General del Insalud de los años 80, Francesc Raventós, quien señalaba cuales eran los procedimientos precisos para la gestión adecuada de los Servicios sanitarios.

Los nuevos retos en la gestión de pacientes, y una mayor orientación del hospital al cliente, han delimitado, conjuntamente con la generalización de los conceptos de eficiencia y calidad, y la necesidad de contener los costes sanitarios, la urgencia del cambio en los hospitales, tal y como se concluía en el informe «El futuro de la Sanidad Europea», publicado en 1995.

Que es necesario «empresarizar» los hospitales públicos, lo sugería ya en 1988, P.F. Drucker en el Harvard Business Review, al afirmar que «la gran empresa de finales de siglo se parecerá a un tipo de organización a la que managers y Escuelas de negocios, no prestan mucha atención: la organización hospitalaria».

La introducción en la gestión del hospital de conceptos como el mercado, la competencia, el marketing, la cuenta de resultados y hasta los beneficios, hacen imprescindible que se introduzcan técnicas y modelos de gestión de procedencia empresarial, ya en uso en nuestro País, tales como la planificación y dirección estratégicas, la descentralización y microgestión de servicios, la gestión clínica o la utilización de la reingeniería de procesos o el outsourcing por citar algunos ejemplos.

Afrontar estos cambios requerirá sin duda alguna, llevar a cabo cambios sustanciales en el modelo organizativo del hospital, comenzando por la propia estructura directiva, por lo que habrá que establecer ya que el actual organigrama vigente de los hospitales públicos (R.D. 521/87), deberá archivarse definitivamente, y considerar que en un marco de plena autonomía de gestión, cada hospital diseñará su propio organigrama, pero eso si, admitiendo como idea general, la necesidad de su horizontalización, tendiendo hacia estructuras organizativas por línea de producto, en las que el protagonismo de los responsables de línea sea mucho mayor, y la relación directivos-jefes de producto, menos jerárquica y más funcional u operativa que en el pasado. 
El Hospital cumple todas las características que definen a las organizaciones complejas tal y como las definía S. Berr, y la profundidad de los cambios necesarios en la gestión del hospital para alcanzar su configuración como empresa, exigirán, de llevarse a cabo en estos términos, un nuevo perfil de los directivos hospitalarios, abandonando perfiles que pudieron servir en el pasado, y caracterizado por:

1.- Estar cualificado profesionalmente a través de una formación en gestión general de empresas y específica en gestión hospitalaria, por Escuelas públicas o privadas acreditadas, lo que permitirá la «real profesionalización directiva» de los gestores hospitalarios públicos.

2.- Será clave en cualquier caso el profundo conocimiento de la realidad sanitaria y hospitalaria.

3.- Precisará dotes de liderazgo notables, pero a la vez importante capacidad de diálogo y negociación.

4.- En este modelo más empresarizado, primarán la capacidad de innovación e iniciativa para la toma de decisiones.

Las habilidades directivas definidas como necesarias para un directivo por H.Mintzberg en 1.973 siguen siendo válidas hoy, lo mismo que el pensamiento necesario en el mundo actual de la empresa desarrollado por J. Champy en 1996, en el mundo de la gestión hospitalaria presente y futura.

\section{La participación de los profesionales}

Se ha repetido hasta la saciedad en los últimos años, que existen niveles elevados de frustración y desencanto acumulados entre médicos, enfermeras y otro personal del S.N.S., y que responde a aspectos diversos, algunos de los cuales reflejamos a continuación:

- Envejecimiento de plantillas y escasa movilidad.

- Inexistencia de concursos públicos de especialistas y niveles de interinaje excesivos.

- Carácter vitalicio de las jefaturas y no desarrollar la Orden Ministerial de promoción y evaluación periódica (4 años).

- No desarrollar sistemas de incentivación discriminativos en función de resultados (eficacia y eficiencia).

- Pérdida de poder adquisitivo de los profesionales. 
La dirección profesionalizada del hospital.....

A nivel de macropolítica sanitaria, no se ha desarrollado lo previsto en la Ley General de Sanidad de 1986: no se ha elaborado una ley básica de ordenación de las profesiones sanitarias, no se ha aprobado un nuevo Estatuto Marco, más adaptado a los tiempos que corren, y los cambios asistenciales y organizativos de los Centros sanitarios, y por último, no se ha desarrollado un modelo de carrera profesional para médicos y enfermeras, que posibilitará la promoción efectiva de estos profesionales.

Pudiera ser que estas omisiones tengan que ver con el elevado número de médicos y enfermeras existentes en España comparativamente con los Países más desarrollados de nuestro entorno, si bien no es tan elevado si lo consideramos porcentualmente sobre el total de trabajadores de cada país.

En cualquier caso, parece evidente la inexistencia de políticas de personal, suficientemente claras y motivadoras en nuestro S.N.S. en su conjunto ni a nivel de Áreas sanitarias, lo que conlleva desarrollar simplemente una gestión de personal consecuencia de una política de corte administrativista y universal.

Además, han surgido agravios comparativos graves desde el inicio de las trasferencias sanitarias a las CC.AA, donde se han formalizado con los sindicatos «Acuerdos de condiciones laborales y salariales» discriminativos con los profesionales del territorio administrado por Insalud, para la misma categoría y función, incluso en la valoración de méritos profesionales para el acceso a plazas por concurso público libre.

Por último, resulta cada vez más complicado aplicar normativas generales para situaciones asistenciales y organizativas cada vez más diferenciadas: niveles y tipologías de hospitales, supuestos de atención continuada diversos, dedicaciones diferentes, etc....

Existe, por tanto, un vacío normativo de entrada en el S.N.S., que debiera elaborarse y consensuarse a través del Consejo Interterritorial de Salud, máximo órgano de coordinación con competencia en estos $\mathrm{y}$ otros asuntos a nivel estatal.

Pero existen otros elementos de insatisfacción acumulada entre los profesionales como quedó reflejado en la pasada huelga médica de 1995, fundamentalmente a nivel hospitalario, en buena medida atribuibles a la Administración sanitaria, que resumo a continuación:

- Desconexión con los equipos directivos.

- Rutinización del trabajo en entornos físicos inadecuados y medios técnicos obsoletos.

- Autoritarismo e incomunicación de algunos jefes de Servicio.

- Desconocimiento de criterios de valoración de su trabajo. 
Hecho este análisis, más o menos acertado, pero desde luego en línea con otras aportaciones hechas en estos últimos años por distintos sectores de la Sanidad española, parecen lógicas sus consecuencias:

- Desmotivación y desarraigo con la empresa (Servicio de Salud, Hospital, C. Salud).

- Pérdida del concepto de «trabajo en equipo» básico a nivel hospitalario.

- Fuga de profesionales valiosos hacia el sector privado o compartición negativa.

- Absentismo laboral elevado.

- Inestabilidad profesional.

\section{Medidas fundamentales a considerar y participación de los profesionales}

Además de la ya mencionada adecuación de la normativa básica en materia de recursos humanos para todo el S.N.S., y el diseño de políticas de personal, a nivel de los Servicios de Salud transferidos y el propio Insalud, que contemplen los pilares básicos de cualquier política de personal que se precie de serlo (salarial, formativa, disciplinaria, régimen laboral y de contratación, incentivación y promoción profesional y ventajas sociales), se requieren con carácter general y con carácter descentralizado, de Área de Salud y de Centro, nuevos planteamientos, algunos de los cuales reflejo a continuación:

- Mayor participación de los profesionales.

- Nuevas formas organizativas en los hospitales: gestión clínica, unidades clínicas, coordinadores asistenciales, comisiones mixtas y comisión de objetivos.

- Programas de formación continuada de médicos y enfermería y reacreditación de profesionales.

- Desarrollo de mecanismos de promoción interna y carrera profesional.

- Pérdida del carácter vitalicio de jefaturas de Servicio y Unidad.

En todo caso, la participación de los profesionales (de todos) es una necesidad ineludible, sin que ello signifique convertir a todos ellos en gestores, sino que manteniendo o mejorando su cualificación profesional, implicarles en mayor medida en la gestión cada vez más compleja de los Centros sanitarios, particularmente la de los hospitales.

Como bien dice V. Ortún, si gestionar quiere decir «hacer cosas mediante personas», cuanto mayor sea la autonomía profesional, menor será la autoridad de la Gerencia. 
Las nuevas tendencias de gestión apuntan hacia el desarrollo de programas de microgestión sanitaria, a través de proyectos de gestión clínica, en los que los facultativos y enfermeras/os son protagonistas de excepción.

Esta participación en la gestión sólo será posible por otro lado, si los Jefes de Servicio y Unidad, trasladan a sus facultativos y enfermeras la información que reciben de las Direcciones de los Centros, en mi criterio cada vez mayor, tal vez exhaustiva en ocasiones, estableciendo a su vez una dinámica interna mucho más participativa que en el pasado (discusión de objetivos de Servicio a través de Comisiones de objetivos, desarrollo de la Especialidad, compromisos con la Dirección, protocolización de técnicas, audits de calidad, etc....).

No es infrecuente el Jefe de Servicio «incomunicado» con el resto de profesionales del Servicio, y con la Dirección del Centro por «voluntad propia», aunque se asigne sistemáticamente la responsabilidad de esa incomunicación a la Dirección del Centro asistencial.

Esta nueva cultura de participación y corresponsabilidad debe armonizarse a la mayor brevedad con un proceso de reacreditación profesional (no es oro todo lo que reluce), con evidente protagonismo de las Sociedades científicas y Comisiones Nacionales de cada Especialidad, $\mathrm{y}$ del diseño de una carrera profesional de médicos y enfermeras, siguiendo modelos ya probados en otros países, como el Reino Únido o en el nuestro propio ( $\mathrm{H}$. Clinic de Barcelona y $\mathrm{H}$. Gregorio Marañón de Madrid), o poner en práctica las propuestas presentadas en su día por el propio Ministerio de Sanidad y Consumo:

- Separación del desempeño administrativo de cargo de la categoría profesional.

- Gradualización del acceso a la categoría inmediatamente superior.

- Número de categorías profesionales limitado (3-4).

- Horizontalización de la organización interna de centros y servicios, y supresión del carácter vitalicio de jefaturas.

- Autonomía y responsabilización de los profesionales e incentivación ligada a resultados.

Sea cual sea el diseño final, su necesidad es absoluta y urgente, paralelamente al cambio organizativo que se propugna fundamentalmente en los hospitales, propiciado por la Ley 15/97, de nuevas fórmulas de gestión hospitalaria, posibilitando mayores cotas de autonomía de los Centros hospitalarios, ya cristalizada en Fundaciones y Empresas públicas en Insalud y Servicios de Salud autonómicos.

El S.N.S. no puede permitirse contar con magníficos profesionales eternamente relegados a una adjuntía hospitalaria si sus capacidades clínicas, docentes, investigadoras o de gestión les posibilitan para mayores empresas. 
No es permisible la fuga de estos profesionales cualificados del sector público ni la tradicional "compartición resignada» con el trabajo privado que suele ir casi siempre en detrimento de esa cualificación, y de la calidad asistencial, cuando no en actitudes negativas en la relación con los pacientes, por otro lado cada vez más exigentes con los profesionales y el Sistema Sanitario.

Considero necesaria y urgente la introducción de las siguientes medidas para acabar con la actual desmotivación e insatisfacción de los profesionales sanitarios:

- Actualización del marco legal del S.N.S.:

- Ley de Ordenación de las profesiones, Estatuto Marco de mínimos y aplicación de O.M. aprobadas.

- Desarrollar una política de personal aplicable con carácter descentralizado a nivel de Área o Centro.

- Desarrollar un modelo de carrera profesional por categorías (3-4), que contemple los niveles asistenciales y los de gestión, por separado, siendo estos últimos revisables.

- Supresión del carácter vitalicio de las Jefaturas de Servicio, evaluándolas periódicamente (4 años).

- Vincular a los profesionales con la Empresa, propiciando su participación activa en la gestión.

- Establecer criterios de valoración del trabajo claros e incentivar a los profesionales en función de su eficacia y eficiencia.

Todo ello, para concluir, en un marco de encuentro necesario entre directivos profesionalizados y despolitizados, estables al menos por períodos razonables de gestión (4-8 años) o relevables exclusivamente por criterios objetivos (resultados), y profesionales hospitalarios motivados, incentivados y evaluados igualmente periódicamente en función de criterios de eficacia y eficiencia.

\section{Bibliografía}

1 Moreu, F. Todo Hospital. 1989.

2 Informe: El Futuro de la Sanidad en Europa. 1995.

3 DRUCKeR, P. Harvard Business Review. 1988.

4 R. Decreto 521/87. Ministerio de Sanidad y Consumo. B.O.E. 16-04-1987.

5 BERR, S. The heart of enterprise. 1979.

6 La naturaleza del trabajo directivo. Mintzberg. Ariel 1973.

7 Ley 15/97, de Nuevas Formas de Gestión Hospitalaria. B.O.E. 26-04-1997. 